\title{
Evaluation of Toothbrush Wear on Toothbrushing Efficiency
}

Rayia Jasim AL-Naimi BDS, MSc (Assist. Prof.)

\author{
Dept of Pedod, Orthod and Prev Dentistry \\ College of Dentistry, University of Mosul
}

\begin{abstract}
Aim of the study: is to assess the influence of toothbrush wear on plaque index (PI) and gingival (GI) index. Materials and Methods: twenty dental students participated, before the beginning of the study, all the students received a prophylactic scaling and polishing by the operator, the PI and GI were recorded at the starting point T0, each student received an identical toothbrush and toothpaste and were instructed to brush twice daily, after one month at T1, the students were randomly divided in to two groups, group no. 1 used the same brush provided at T1, while group no. 2 substituted the toothbrush at each monthly examination. Recalls were scheduled after one (T1), two (T2) and three months (T3), the plaque and (PI) gingival index (GI) of Loe and Sillness, in addition to Rawls et al index of wear for toothbrush were measured at each monthly examination. Results: showed that from T0 to T3 that the PI and GI were increasing with statistically significant difference in between each group. In comparing between the two groups PI showed a significant difference at T2 and T3, and although mean values of GI in group not changing toothbrushes were slightly higher, significant difference was observed at T3 only. The WI had a statistically significant difference as toothbrush bristles deteriorated, and there was a positive relationship between the PI and WI in the group of students that did not change their toothbrush because as the toothbrush bristles splayed and deteriorated, the plaque values increased. Conclusion: it can be therefore concluded from the results obtained in this study, that the capacity to remove dental plaque is much related to toothbrush wear.

Key Words: toothbrush wear, splaying, dental plaque, gingival health.
\end{abstract}

AL-Naimi RJ. Evaluation of Toothbrush Wear on Toothbrushing Efficiency. Al-Rafidain Dent J. 2009; 9 (1):51-56.

Received: 9/12/2007

Sent to Referees: 9/12/2007

Accepted for Publication: 18/2/2008

\section{INTRODUCTION}

The extent to which a toothbrush is worn out as evidenced by bristle wear is an important determinant of cleaning ability, ${ }^{(1,2)}$ there have been many studies that investigated the effect of toothbrush wear on plaque removal, ${ }^{(3-8)}$ one of the difficulties encountered in literature may be attributed to the difficulty in achieving a standard and objective method for evaluating toothbrush wear, ${ }^{(9)}$ according to patients ${ }^{(4)}$ and dental operators, ${ }^{(2,10)}$ the splaying, spreading and bending of toothbrush bristles are the main indicators of wear, and these are the signs of toothbrush replacement.

According to many studies, dentists suggests that the average replacement time of a toothbrush ranges from 1-3 months. $(2,4,7,11)$

The aims of this study is to determine the effect of worn toothbrushes on plaque and gingival indices in a group of dental students and to see if worn toothbrushes had a reduced ability to remove plaque in comparison with new ones.

\section{MATERIALS AND METHODS}

Twenty college students in their final year were recruited for a 3 month duration clinical study, the inclusion criteria was: aThe students were healthy and did not consume any medication that could impair their usual level of oral hygiene. b- Non of the participants was a smoker. c- Non of the participants was wearing an orthodontic appliance. The design of the study is shown in Table (1), at T-1 Which was 2 weeks prior to the beginning of the study, patient selection ( 10 males and 10 females with an age ranging between $22-24$ years) 
was performed, all the individuals had a prophylactic scaling and polishing by the operator and home care instructions were reinforced to obtain an adequate level of oral hygiene.

Table (1): The Design of the Study

\begin{tabular}{|c|c|c|c|c|}
\hline T-1 & T0 & T1 & $\mathrm{T} 2$ & T3 \\
\hline $\begin{array}{l}2 \text { weeks be- } \\
\text { fore T0 pro- } \\
\text { fessional } \\
\text { scaling and } \\
\text { oral hygiene } \\
\text { motivation. }\end{array}$ & $\begin{array}{l}\text { Toothbrushes } \\
\text { are issued, } \\
\text { start of ex- } \\
\text { periment, PI } \\
\text { and GI are } \\
\text { recorded. }\end{array}$ & $\begin{array}{l}1 \text { month later, random dis- } \\
\text { tribution of the subjects in to } \\
2 \text { groups. } \\
\text { Group } 1 \text { not changing } \\
\text { toothbrush, brush was col- } \\
\text { lected and measured PI, GI } \\
\text { recorded. } \\
\text { Group } 2 \text { toothbrush collec- } \\
\text { tion measured and replaced } \\
\text { with new one. }\end{array}$ & $\begin{array}{l}2 \text { months later, Group } 1 \\
\text { PI and GI recorded and } \\
\text { measurement } \\
\text { toothbrush. } \\
\text { Group } 2 \text { toothbrush col- } \\
\text { lection and measurement } \\
\text { and replaced, PI and GI } \\
\text { recorded. }\end{array}$ & $\begin{array}{l}3 \text { months } \\
\text { later, col- } \\
\text { lection and } \\
\text { measure- } \\
\text { ment of all } \\
\text { toothbrushe } \\
\text { s, PI and } \\
\text { GI re- } \\
\text { corded in } \\
\text { all subjects }\end{array}$ \\
\hline
\end{tabular}

At T0 the Plaque index of Löe and Sillness $1963^{(12)}$ and Gingival index of Loe and Sillness $1964^{(13)}$ were recorded on the four surfaces of the index teeth, if the index tooth was missing, readings from the adjacent distal tooth was recorded. Each of the 20 subjects received the same brand of a tooth brush that was commercially available in the market (Formula system manufactured by PT Ultra Prima Abadi, Jakarta, Indonesia) and tooth paste (Formula manufactured by PT Ultra Prima Abadi, Jakarta, Indonesia). The tooth brush is designed with 4 rows of bristles with a total of 46 tufts, 44 mono filaments per tuft, before tooth brush was used, each one was measured, by anchoring the head of the tooth brush in a vice illuminated by a constant light (halogen 150W) and measured with a digital Caliper with an accuracy of measurement up to one hundredth of a millimeter. According to Rawls et al (1989), ${ }^{(14)} 5$ measurements of each tooth brush were recorded as shown in Fig. (1) in each visit.

The students were instructed to brush twice daily using only the tooth brush and toothpaste given using a modified Bass technique (Bass 1954) ${ }^{(15)}$ and to refrain from using dental floss, mouth washes or any other plaque removal aids .At T1, the subjects were randomly divided into two groups, group number 1 (4 males, 6 females) were instructed to brush for the whole period of the study with a toothbrush initially provided at $\mathrm{T} 1$.

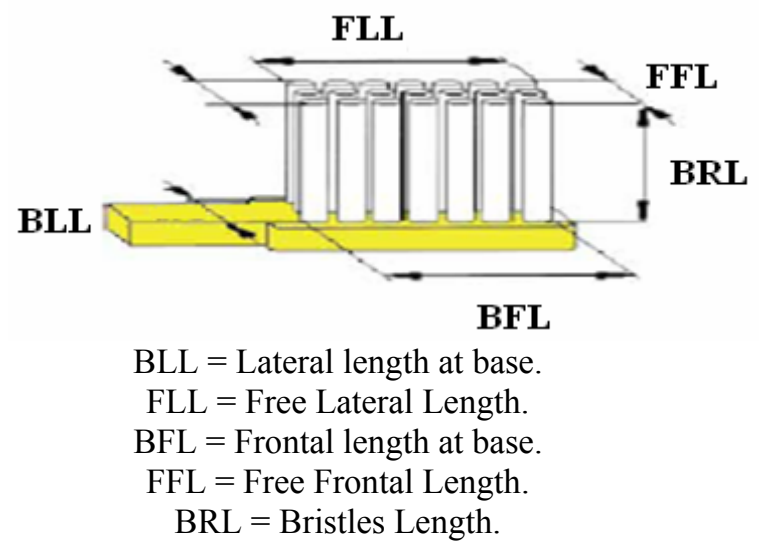

Figure (1): Toothbrush dimension measurements.

In contrast, group number 2 students (6 males, 4 females) were instructed to brush with the tooth brush received at $\mathrm{T} 0$ for one month only, after that the toothbrush was substituted with a new one at each monthly examination. All subjects were clinically evaluated at one month (T1), two months (T2) and three months (T3) intervals, after consignment of the toothbrush and the PI and GI were recorded, instructions about oral hygiene procedures were reinforced by each monthly examination. The toothbrushes that were not changed were measured by the operator at T1, T2 and T3 and index of wear (WI) was calculated according to the 
formula suggested by Rawls et al $(1989)^{(14)}$ :

$$
W I=\frac{F L L-B L L+F F L-B F L}{B R L}
$$

The PI and GI values that were recorded at each clinical evaluation at $\mathrm{T} 0$, $\mathrm{T} 1, \mathrm{~T} 2$ and $\mathrm{T} 3$. The results were analyzed to determine significant differences within the groups using repeated measure analysis, between the two groups using unpaired $\mathrm{T}$ test, the results were significant when $\mathrm{P}$ $\leq 0.5 \%$. A quadratic regression analysis was used to show the relationship between the wear and plaque indices.

\section{RESULTS}

At base line T0, PI and GI values did not exhibit any statistically significant difference between the 2 groups, but it can be seen in Table (2) and (3) that the mean values of the PI and GI began to increase with in the same groups so the PI in group not changed toothbrush increased from
0.38 to 0.56 with very highly significant difference $\mathrm{P}<0.001$, also the GI in the same group increased from 0.40 to 0.54 with highly significant difference. The PI in group of changing toothbrush changed from 0.39 to 0.47 with significant differences between first and last visits, while the GI changed from 0.38 to 0.46 with highly significant differences between first and last visit .In comparing between the PI and GI in group that did not change toothbrush and those that changed, there were no significant differences regarding PI in the first score taking, later on in second and third month significant difference was seen $(\mathrm{P}<0.05)$, regarding GI, no significant differences were seen between the 2 groups in the first 2 scores, but in the final recording the GI in the group not changing toothbrush was higher 0.54 than the group with changed toothbrush 0.46 with significant difference.

Table (2): Comparison of Plaque Index between the Group of Changing Toothbrush and Group not Changing Toothbrush.

\begin{tabular}{cccc}
\hline $\begin{array}{c}\text { Time } \\
\text { (month) }\end{array}$ & $\begin{array}{c}\text { Group of not changing } \\
\text { toothbrush (n=10) }\end{array}$ & $\begin{array}{c}\text { Group of changing } \\
\text { toothbrush (n=10) }\end{array}$ & p-value \\
\hline 0 & $0.38 \pm 0.02$ & $0.39 \pm 0.02$ & $0.228(\mathrm{NS})$ \\
1 & $0.43 \pm 0.03^{* *}$ & $0.41 \pm 0.03^{* *}$ & $0.216(\mathrm{NS})$ \\
2 & $0.52 \pm 0.05^{* *}$ & $0.45 \pm 0.03^{* *}$ & $0.028(\mathrm{~S})$ \\
3 & $0.56 \pm 0.03^{* * *}$ & $0.47 \pm 0.03^{* *}$ & $0.010(\mathrm{~S})$ \\
\hline
\end{tabular}

$\mathrm{NS}=$ Not significant

** significant difference from first and previous measurements at $\mathrm{p}<0.01,{ }^{* * *} \mathrm{p}<0.001$

Table (3): Comparison of Gingival Index between the Group of Changing Toothbrush and Group not Changing Toothbrush.

\begin{tabular}{|c|c|c|c|}
\hline \multirow{2}{*}{$\begin{array}{c}\text { Time } \\
\text { (month) }\end{array}$} & \multicolumn{2}{|c|}{ Mean \pm SD } & \multirow[b]{2}{*}{ p-value } \\
\hline & $\begin{array}{c}\text { Group of not changing } \\
\text { toothbrush }(n=10)\end{array}$ & $\begin{array}{l}\text { Group of changing } \\
\text { toothbrush }(n=10)\end{array}$ & \\
\hline 0 & $0.40 \pm 0.02$ & $0.38 \pm 0.02$ & $0.201(\mathrm{NS})$ \\
\hline 1 & $0.47 \pm 0.05^{* *}$ & $0.39 \pm 0.03 * *$ & $0.306(\mathrm{NS})$ \\
\hline 2 & $0.48 \pm 0.06^{*}$ & $0.45 \pm 0.04 * * * \bullet \bullet$ & $0.755(\mathrm{NS})$ \\
\hline 3 & $0.54 \pm 0.05^{* * *}$ & $0.46 \pm 0.06^{* * *}$ & $0.025(\mathrm{~S})$ \\
\hline
\end{tabular}


Regarding toothbrush wear, an increase in the WI values was registered from $\mathrm{T} 0$ to T3 in group no. 1 that did not change toothbrushes with very highly statistically significant difference $(\mathrm{P} \leq 0.001)$ as shown in Table (4), the quadratic regression analysis Figure (3) showed a statistically significant relationship between WI and PI of individuals that did not change their toothbrush, various entanglement styles and splaying were observed in Figure (2) in the toothbrush bristles.

Table (4): Index of Wear in Group not Changing Toothbrush.

\begin{tabular}{cc}
\hline Time (month) & Mean \pm SD \\
\hline 0 & $0.017 \pm 0.0082$ \\
1 & $0.141 \pm 0.0053^{* * *}$ \\
2 & $0.389 \pm 0.107^{* * *} \bullet \bullet$ \\
3 & $0.572 \pm 0.074^{* * *} \bullet \bullet$ \\
\hline
\end{tabular}

\footnotetext{
*** significant difference from first measurement at $\mathrm{p}<0.001$,

$\bullet$ • significant difference from previous measurement at $\mathrm{p}<0.001, \bullet \bullet<0.01$
}

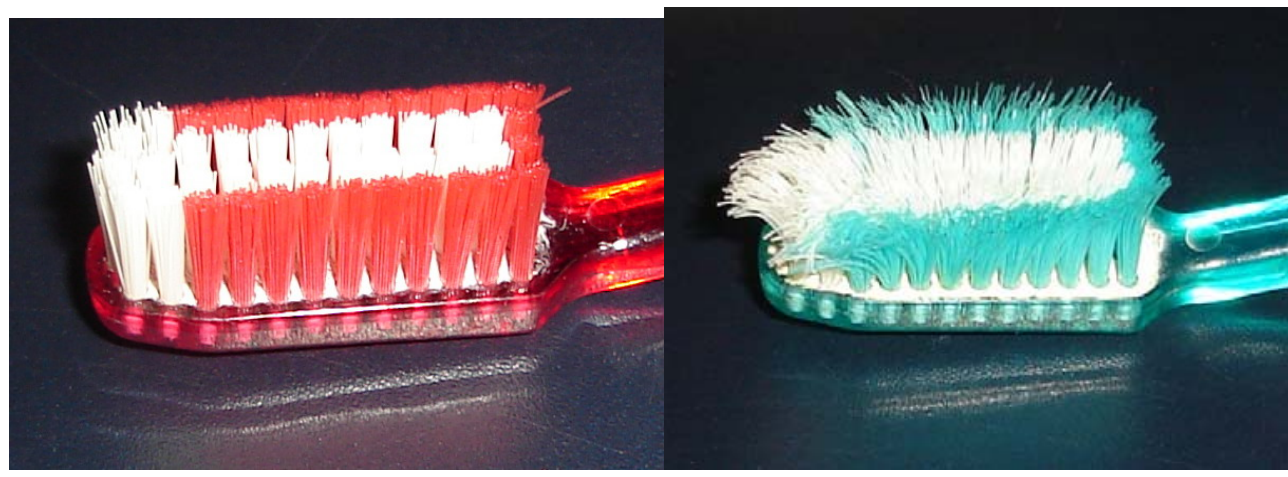

(A)

(B)

Figure (2): Toothbrush Appearance after (A) One Month, (B) Three Months.

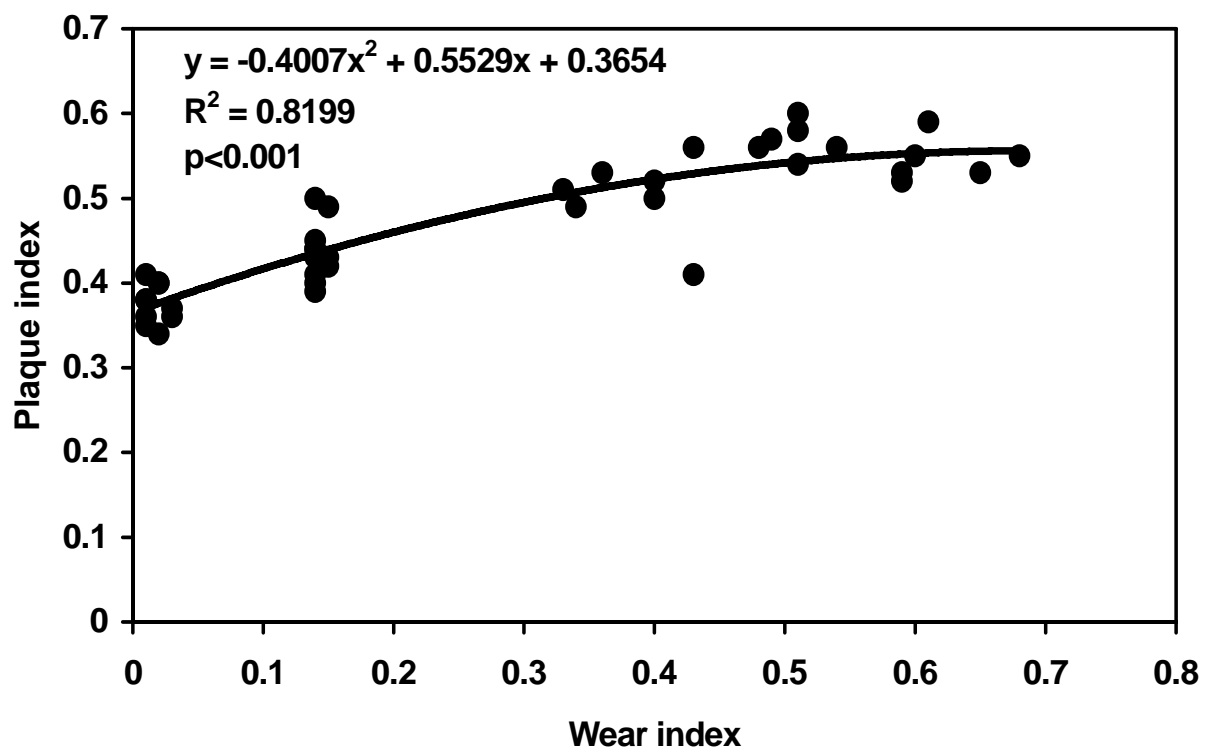

Figure (3): Relationship between Wear Index and Plaque Index in Group not Changing Toothbrush. 
Plaque induced gingivitis continues to be prevalent among children, adolescents and adults world wide and the importance of prevention, early diagnosis, and treatment of gingivitis in adults to prevent progression into advanced periodontal disease is emphasized in the dental literature, ${ }^{(16)}$ the role of dental bacterial plaque has been established ${ }^{(17)}$ and the best approach to manage periodontal disease is prevention, followed by early detection and treatment. Mechanical plaque removal with a manual toothbrush remains the primary method of maintaining good oral hygiene and the most affordable method for the majority of the population, ${ }^{(18)}$ the results obtained from this study suggests, with in limit of the present research, that the capacity to remove plaque is much related to toothbrush wear, a statistical analysis was used to compare the plaque, gingival and toothbrush wear indices in a group of dental students who monthly substituted their toothbrush and those who did not, the analysis showed that in the 2 groups Tables (2) and (3), the PI and GI indices were relatively low in the beginning $\mathrm{T} 1$, this may be attributed to the reason that all the subjects participating in the study had received a prophylactic scaling two weeks prior to the study, then both indices increased, PI showed increasing values between subject of each group as it increased from 0.38 to 0.56 in group not changing toothbrushes, and from 0.39 to 0.47 in group changing tooth brushes while GI increased in the first group from 0.40 to 0.54 and in the second group from 0.38 to 0.46 with statistically significant differences with in each group through the duration of the study, the same thing can be observed in GI in this group. In comparing between the two groups, there was no significant difference in PI at $\mathrm{T} 0$ and $\mathrm{T} 1$, but later on significant difference was observed at $\mathrm{T} 2$ and $\mathrm{T} 3 \quad(\mathrm{P}<0.05)$, as toothbrush wear increased more plaque was observed in individuals that did not change their brush, and although GI values were slightly higher in individuals that did not change their toothbrush, significant differences between the 2 group was only observed at $\mathrm{T} 3$, the result are in agreement with other studies ${ }^{(3,8,11)}$ and in contrast to that of other studies, ${ }^{(5,6,19,20)}$ the differences may be related to variables type of toothbrush ${ }^{(18)}$ abrasive materials present in the toothpaste, ${ }^{(21)}$ this was the reason for standardizing the method of toothbrushing and type of toothpaste used by the subjects or the type of indices used to measure the plaque. ${ }^{(19,20)}$

The individuals that participated in this study were all dental students that were subjected to an accurate monthly examination similar to the study by Daly et $\mathrm{al}^{(22)}$, on the other hand Sfroza et $\mathrm{al}^{(6)}$ preferred to recruit non dental students stating that students previous knowledge of problems of oral hygiene may presumably have influence on the results obtained.

It can be observed in Table (4) and Figure (2) that there was a highly statistically significant difference in the toothbrush wear index as toothbrush bristles deteriorated, as it changed from 0.017 at $\mathrm{T} 1$ to 0.572 at T3. The wear index is the average increase in brush head dimensions normalized for maximum bristle length, and is dimensionless, wear rating is a subjective means of classifying the increasing severity of deterioration on a graduated scale. There have been many studies that were conducted to determine the efficiency of toothbrush on plaque removal using artificially worn toothbrushes, ${ }^{(11,22,23)}$ however it can be assumed that the use of artificially worn toothbrushes may not be considered an objective method to evaluate the efficacy of plaque removal since it only approximates the characteristics of naturally worn toothbrushes, as a matter of fact, even if artificially obtained splaying and fraying closely resembles the characteristics of naturally worn bristles, other factors may influence and modify intrinsic characteristics of the bristles such as the rubbing against the tooth surface, its interaction with food particles and bacterial plaque, abrasive characteristics of the tooth paste and natural aging of the bristles.

Figure (3) revealed that there was a statistically significant relationship between the toothbrushes and plaque values that were increasing in group of students that did not change toothbrushes, therefore it is recommended to replace the tooth-brush as soon as bristle splaying and matting is ob- 
served because it looses its cleaning ability.

\section{CONCLUSION}

Toothbrushes can loose their ability to properly remove plaque after a period of three months, it is therefore recommended for individuals to change their toothbrushes after this period of time.

\section{REFERENCES}

1. Rawls HR, Casella R, Mk-way Tulloch NS. An in vitro and in vivo study of toothbrush bristle splaying. $J$ Dent Res. 1993; 72(5): 947-952.

2. Daly CG, Marshall RI, Lazarus R. Australian dentists views on toothbrush wear and renewal. Austr Dent J. 2000; 45(4): 254256.

3. Glaze P and Wade B. Toothbrushes age and wear as it relates to plaque control. $J$ Clinic Period. 1986; 13: 52-56.

4. Dean D, Beeson L, Cannon D, Plunket C. Condition of toothbrushes in use: correlation with behavioral and socioeconomic factors. Clinic Prevent Dent. 1992; 14: 1418.

5. Daly CG, Chappie CC, Cameron AC. Effect of toothbrush wear on plaque control. J Clinic Period. 1996; 23: 45-49.

6. Sfroza NM, Rimondini L, di-Mena F, Carmoli C. Plaque removal by worn toothbrush. J Clinic Period. 2000; 27: 212-217.

7. Tan E, Daly C. Comparison of new and 3 month old toothbrushes in plaque removal. J Clinic Period. 2002; 29(7): 645-650.

8. Confronti NJ, Cordero RE, Liebman J, Bowman JP, Putt MS, Kuebler DS, Davidson KR, Cugini M, Warren PR. An investigation in to the effect of three months clinical wear on toothbrush efficacy : results from two independent studies. $J$ Clinic Dent. 2003; 14(2): 29-33.

9. Kreifeldt J, Hill P, Calisti L. A systematic study of the plaque removing efficiency of worn toothbrushes. J Dent Res. 1980; 59: 2047-2055.

10. Abraham N, Cirincione U, Glass R. Dentists and dental hygienists attitude Towards toothbrush replacement and maintenance. Clinic Prevent Dent. 1990; 12:28-33.

11. Warren PR, Jacobs LDS, Low M, Chater $\mathrm{B}$ and King D. A clinical investigation in to the effect of toothbrush wear on efficacy. J Clinic Dent. 2002; 13: 119-124.

12. Loe $\mathrm{H}$ and Sillness P. Periodontal disease in pregnancy: Prevalence and Severity. Acta Odontol Scand. 1963; 21: 533- 551.

13. Silness $P$ and Loe H. Periodontal diseases in pregnancy II correlation between oral hygiene and periodontal condition. Acta Odontol Scand. 1964; 22: 121-135.

14. Rawls H, Mkway, Tulloch NS, Casella RE and Cosgrove R. The measurement of toothbrush wear. J Dent Res. 1989; 68: 1781- 1785.

15. Bass CC. An effective method of personal hygiene. $J$ of Louisiana Med Society. 1954; 106: 100-105.

16. Bimstein E. Periodontal health and disease in children and adolescents. Pediatr Clin North Am. 1991; 38(5): 1183- 1207.

17. Breuer MM, Cosgrove RS. The relationship between gingivitis and plaque levels. J Periodontol. 1989; 60(4): 172-175.

18. Terezhamly GT, Samer MA, Bartizek RD, Biesbrock AR. Plaque removal efficacy of a prototype manual toothbrush versus an ADA reference manual toothbrush with and without dental floss. $J$ Contemp Dent Practice. 2005; 6 (3): 1-12.

19. Hedge PP, Ashok KB, Ankola AV. Toothbrush age, wear and plaque control. Indian J Dent Res. 2005; 16 (2): 61-64.

20. Helderman WHVP, Kyaing MM, Rosema NAM, Weijden GA, Hof MA. Plaque removal by young children using old and new toothbrushes. J Dent Res. 2006; 85 (12): 1138- 1142.

21. Lentz DL, Mcdaniel MD, Tolbert WE, Dean DH. Toothbrush abrasion caused by different dentifrices. Quintess Int. 1991; 22(12): 985-988.

22. Daly CG, Chapple CC, Cameron AC. Effect of toothbrush wear on plaque control. J of Clinic Periodontol. 1996; 23: 2530.

23. Wakamatsu Y, Kakuta K, Ogura H. Wear test combining simulated occlusal wear and toothbrush wear. Dent Mater J. 2003; 22 (3): 383-396. 